\title{
The Fable of Recognition: A Study of Northrop Frye as a Prophet
}

\author{
Peng Li \\ The Department of Foreign Languages, Jiangning Campus of China Pharmaceutical University, \\ E-mail:lipengxinquan@163.com
}

Received: June 15, 2011 Accepted: July 2, 2011 doi:10.5539/elt.v4n3p54

\begin{abstract}
Northrop Frye is a famous Canadian literary critic, but his fame enjoyed its peak in the $50 \mathrm{~s}$ and $60 \mathrm{~s}$ as a representative of the myth-archetypal school of literary criticism. When deconstruction was on the rise, it faded greatly, and what's more, sometimes Frye was taken as a notorious obstinate structuralist. In fact, even his fame as an archetypal critic is not based on a genuine grasp of his thought, and he himself declared that he resented being classified into other schools which he did not belong to. This misunderstanding is an outcome of the difference of awareness between him and the logical and reasoning literary critics, with the former taking the free flow of life's energy, the full function of the vital but unpredictable Holy Spirit as the Truth while the latter holding that truth is a correspondence between mind and the outer world, be it social, psychological or natural. This article is an attempt at a full comprehension of the Spirit, and based on this, a full understanding of Frye and his should-be influence on our literary and actual life. It first tries to elucidate the Spiritual dimension and the life state when it is forgotten or refused, and then it devotes itself to the discovery of this dimension and the entering into the Spirit; which is a major structure of all aspects of Frygian thoughts.
\end{abstract}

Keywords: Holy Spirit, Spiritual identity, Creative energy, Metaphor, Metamorphosis, Recognition

\section{Introduction}

When in 1947 Northrop Frye described the characteristics of Blake's artistic works (FS 13-4) and the public reception of him as an artist (FS 3-5) and when he admitted Blake as his guru and that his life style had been on an unconscious level imitating him (SM 16), surely, he hadn't realized that his career and fate as a critic are profoundly the same as those of Blake as an artist. His comment on Blake's works as consistent even from the beginning to the extent that some lines or phrases reappeared forty years later is exactly like Robert Denham's comment on him (Introduction 1) to the effect that we can find the root of his ideas even in his earliest essays, which Denham defined as continuity, but, if we see continuity and discontinuity in Frye's perspective, would be better defined as discontinuity, like proverbial philosophy, "closer to literature than to actual philosophy, because the poet or literary artist seeks, not the unexplored idea, but the inevitable expression of the familiar idea" (WTC 88) and like what Paul emphasized--he was preaching not a different thing but the same thing always (Galatians 1:9).

This, to some, would become a good target to attack, and professor Jerome Bruner's view that Frye hadn't budged an inch in eighteen years but had always been circling around one point is an excellent (insightful to some extent) representative (SM 100). But what is ironic here is that although Frye was circling around one point, critics always focus on the circumference of the circle and fail to grasp the center, which naturally makes their understanding of Frye both partial and wide of the mark. So, he is, as what he described poets are, always on a stock exchange, which means that his reception, cold or warm, is not based on a full and just evaluation of his thoughts, but on the personal anxiety of the evaluator. First, he was ranked as the head of one of the three most prevailing schools of criticism, i.e. Marxism, psychoanalysis and archetypal criticism, not because of his own argument but because there is an extensive structural analysis which can be easily grasped by logic in Frye's Anatomy of Criticism, a work reflecting less of the core of Frye's insight than any other of his works, the high rank of which is a disaster in that it misled scholars interested in Frye away from the centre to the circumference. Then, "later paradigms and vocabularies of semiotics, structuralism, post-structuralism, and deconstruction swept aside Frye's cosmic designs" (Higdon 223) and Frye was more and more marginalized and even detested as an obstinate structuralist. Now, since culture study is on the rise and because of Frye's words on culture, society and civilization, there seems to be more study of him. But, through this rise and fall, Frye's real argument is still buried underground, eluding our grasp. Just as he said of his guru Blake to the effect that his poetry had never been really appreciated and that it was only by cutting the major part of his works away that literary historians had been able to stuff him into their history as a minor pre-Romantic (FS 3), it is only by casting away the central point of Frye that we see Frye taken by literary theory historians as a myth-archetypal critic. Thus, Abrams took Frye's works as the defense of a literary universe that is 
adapting nature to human needs and desires (Glossary 12-4); Terry Eagleton took his theory as some collective Utopian dream, which is by no means a positive comment; and Xie Shaobo, a Frederic Jameson scholar, took Frye's thought as "aesthetic humanism" (117). The views of all these scholars may have been best summed up by Liu Kang as "structuralism, Utopia and archetype" and that's why he held that there is no innovation in Frye's critical ideas (46-56). But these things, as is said above, are taken as Frye's major points because they are easy for logical comprehension, not because they are really the essence of Frye's thoughts. Robert Denham's Northrop Frye: Religious Visionary and Architect of the Spiritual World is, to me, the most thorough and insightful treatment of Frygian thoughts ever seen and a fruit of years of unremitting research. But his effort to rationalize Frye on the basis of religion and Hegelian dialectic largely diverts the reader's attention from what is really important; and what's more, the form of the book, which is a list of different terms, makes it even harder to discover the shape of Frye, though these terms are really essential.

Why this can be so may be best illustrated by the dialogue between Jesus and Nicodemus in the Gospel of John (John 3). The second birth said by Jesus astonished Nicodemus, for in no way could he comprehend how a man could be born again when he is old and when Jesus told him that a man should be born of water and spirit and that which is born of spirit is like the wind, substantial but unpredictable, he was shocked beyond words. The reason for this is that they are of different worlds and talking about different things. When Nicodemus tried to understand Jesus' words according to his logic, it is sheer non-sense. If Jesus had had the status requiring compulsive understanding, it is predictable that Nicodemus would have rationalized Jesus' words according to his own logic, which would surely be wide of the mark and misleading. Thus, it is not hard to understand why Frye and his guru are so miscomprehended. For both of them, the truth lies not in the correspondence between mind and nature, which they take as a curb of imaginative creativity or life itself, but in the full function of the "Holy Spirit" which is what all the guru's artistic works point to and all the theoretical arguments of the pupil keep returning to. This fact becomes more and more clearly stated in Frye's later works, from his Creation and Recreation to his Bible books. So, it is not views on religion that interpenetrate everything (Denham, Visionary and Architect 2); instead, what permeates all Frye's works is this life, truth and spirit, and the continuity of argument is only a disguise. But seldom has any literary theorist paid much attention to the nature of this Spirit in Blake and Frye's works, which makes it, though a centre, a vacuum which no one has thoroughly, or really, touched at all.

In the following, I will adopt the shape of a fall-and-rise process to trace how "life and spirit" are gradually buried underground and how they can be possibly regained, which is the shape of Blake's poetry, Frye's thoughts and the Bible which is a major source for both of them, with the aim to make it clearer what is the direction of Frye's effort so that Frye's central idea may have its real influence on literary criticism.

\section{Metamorphosis}

\subsection{From Free Flow of Life to Alienation, Fear and Cruelty}

Since, as is said above, the fundamental problem in our understanding of Northrop Frye is that we are in different worlds and when we apply the truth correspondence generated from our logic to him we will infallibly miss the point; the first we should do in order to get to know him is to see in what way we are in different worlds and talking about different things with seemingly the same language. For illustration as well as argument, I now do as Frye tended to do--turn to obvious books (NFCL 65).

First we turn to the story in the Bible accounting the fall of Adam and Eve. Before the fall, we see Adam and the world around him all belong to one spirit which is from Adam and in Adam and belongs to Adam and which has its origin in the breath of God in his nostrils (Genesis 2: 7). This oneness signifies by the fact that it is Adam who is giving names to all around him. Since name in the Bible is spiritual identity, which may be seen in that the shepherd will call his sheep by name (John 10:3) and in that when the resurrected Jesus calls Mary by name, she immediately knows who it is that is speaking to her (John 20: 16); so the giving of names here is a free creative act, is a free Adam creating a spiritual world for himself, or, in another word, he is giving all around him life by breathing his own life into them, which is the same as what God did--breathed life into Adam. So Adam and Eve and all around them are enjoying the spiritual oneness and we see a free flow of life's energy in Adam and a grand spiritual identity in Eden. There is no inside and outside, no subject and object. All are both free beings as well as manifestations of the same unity. Then here comes the snake and these are its words:

"Ye shall not surely die. For God doth know that in the day ye eat there of, then your eyes shall be opened, and ye shall be as gods, knowing good and evil." (Genesis 3: 4-5)

What is important here in the snake's words lies not in, as many believe, that it tells Eve the tree can make her know good and evil but in that with the fruit thereof, she can be like gods, the effect of which is that the sense of oneness disappears and she has gained the sense of otherness and so becomes now an ego, and her eyes are opened so that 
things around her are no longer one with but out of her. The free flow of life's energy turns into a restriction of the spirit. The case is the same with Adam. We may interpret the acceptance of the fruit as the acceptance of Satan's words. The fallen Adam and Eve are different beings now from the unfallen one flesh and spirit and it is hard to imagine that Adam and Eve can feel as they once did. According to Frye (FS 226), the fall and the creation of the physical world are in fact different aspects of the same event. At this moment, their environment is not permeated with their life, but becomes different from them and is alienated and essentially hostile, a threat to their egoistic desires. Free flow of life's energy disappears which means free beings become dependent and under bondage, which may be why God said that the fruit would kill them. So, naturally, what comes next in the story is the behavior of egos: when God comes, they hide themselves away and when God asks about the reason, the man lays blame on the wife and the wife on the snake, which is a lonely and hopeless struggle against the impending doom. Even if no one chases them out of Eden, they have already lost it. In the New Testament we see that God is life (John 1: 1), is light (1 John 1: 5) and is spirit (John 4:24), so the hiding away from God is the reluctance to face their own free state, to return to pure spirit, as is shown in Milton's opinion:

"Liberty is what the will of God intends for man, but it is not anything that man naturally wants, his nature being perverted. What man naturally wants is either mastery or conformity to custom and to what we have been calling the anxiety of continuity." (CP 77),

which is what sin or, we may say, original sin, is in Frye's context--"man's fear of freedom and his resentments of the discipline and responsibility that freedom brings" (GC 232).

This pattern keeps recreating itself all through the Bible. Another we see which is very much clearer is in the story of the prodigal son. When the son asks for his portion of goods, what he actually doing is chasing away the spirit of the family union and gaining the form of an ego through division (Luke 16: 12). His fate, the same as Adam's, would surely be a hopeless and lonely fight to establish himself in an alien environment. This situation may be best illustrated by the myth of Sisyphus in which the hero should enlarge the room of survival for himself by rolling a stone up along a slope but always finds it rolling down upon him once he stops rolling. As in the Bible stone signifies the physical world, the restriction of the Spirit and death itself (FS 224-5), Adam and Eve and the prodigal son, as Sisyphus, all may be seen as having a stone upon their heads, trying to extinguish the imaginative creativity in them. Thus, the function of the snake may be seen as a reminder, telling Adam and Eve that they are from dust after all and should not consider themselves as nobler and as being able to live a free imaginative life and it is in this sense that Satan is called an accuser--"reminding man of his insufficiency and causing him to despair of deliverance" and getting victory when achieves "complete torpor and paralysis of the mind" (FS 67).

This situation of humanity is the same as that which the fallen Macbeth was in. We see his desire to get everything under his tyrannical control and his effort to reduce everybody into predictability, but even if everything was under control he was still in a constant fear that some power would rise up and devour him, which resulted in his desperate annihilation of lives. But life will rise despite this effort; so, though he got assured from the witches that only when two conditions almost impossible to meet--first, the moving of the wood, and, second, the man not born of woman--are met will he be defeated, these conditions were fulfilled indeed: the wood was ordered to be cut down and taken as shade and a device to hide the number of soldiers, and Macduff was not born of woman but "from his mother's womb untimely ripped" (Macbeth: Act 5, Scene 8, Lines 14-6). If we give the conditions a second thought, it's not hard to discover that one is about space and the other about time; thus, the two may be taken as one--the bending of a stubborn nature to the service for human wish. From the time when Macbeth saw the first condition met until the end, the desperate self-assumption that he could control the situation within predictability in the face of inevitable doom and the resultant irony and pathos are the most intense. This Macbeth is precisely the same as the mediocre described by Frye who is good at self-restraint and restraint of others, the former of which is fear and the latter is cruelty. The cruelty and fear, as we see in Macbeth, all are products of the introduction of "otherness" and the disappearance and denial of the Spirit, the unity, the imaginative creativity; thus, "all the cruel are frightened, and all the fearful are cruel" (FS 57).

\subsection{The Spiritual Dimension and the Physical One}

The importance of a male Creator, a female coming from the male and the former transgressing first so that the latter has dominance over her and the one defeating the tyrannical Macbeth being not born of woman, according to Frye (CR 37), has little to do with patriarchal prejudice, although it has been getting exploited to rationalize male power. Frye proposed that it might be better if the West had such gender-free terms as Yin and Yang in classical Chinese philosophy (WP 196), but if he had stood firm on his ground that the centripetal meaning, or the permeating spirit, is more important than centrifugal meanings, he would not have hesitated in suggesting that the symbolism of male and female within the myth has starkly (not "in an element") no connection with social relations of men and women. He stated remarkably clearly that the emphasis on the male "is connected with its resistance to the cyclical fatality of 
all religions founded on mother nature" (CR 38), but if he had been at that time as assertive as he was when composing Fearful Symmetry, he would not have used such a tentative phrase as "be connected with". When Paul compared the relationship of man and wife with Christ and the church and said the wife is the body of the man as the church is the body of Christ (Ephesians 5: 22-33) and when we see the redeemed Jerusalem is metaphorically a bride for Christ, we may sense a uniqueness of the male and female division in the Bible in which the female is a metaphor for the body while the male a metaphor for the spirit. Thus, the woman in Eden is the body of Adam and an incarnation of the female garden and the spirit dwelling in this body and garden is the Spirit of Adam which comes from God the Creator creating with the Spiritually inspired Word.

With this insight, we may find that the importance that the female, the body, should fall first lies in that it assures the security of spirit in man and the possibility for it to renew its free flow; thus, every one of us is spiritually or metaphorically male while the physical world is female. Frye saw the Book of Job as a miniature Bible and so when he said that God's injunction is that Satan could take away everything of Job except for his life we see that the spiritual identity is what gives life to everything and should remain untouched, waiting to regain dominance (SM 240), which should be applicable to the case of Adam too. The effect of Job's friends' preaching is to drive the life away from him and by doing so submit spirit to conformity (SM 235), and Job has done well in sticking to his life and spiritual identity. Also, Macduff, the one who is not born of a woman but untimely ripped out, is the substantial and unpredictable spirit surmounting the tyrannical natural routine (with time and the metaphorically female nature as its main features) and his victory over Macbeth, the one aspiring to extinguish all spirit out of fear and cruelty to ensure predictability, the safety in monotony and stagnation, is again the Spirit's victory over conformity. This again is a picture of the monotonous world as a stone waiting to be rolled back and redeemed by human recreation through imaginative creativity, or, the life and spirit (FS 224-5). So, although Frye didn't talk about the male and female metaphor in the Bible or secular literature in such a bold way, his theory leads well to it, his discussion of the miniature forms an example, and many of his words have a trace of it; so, the above analysis can be taken as both an illustration and a further study or critical application. From the above discussion it may be clear that what metamorphosis means in this part is "humanized creatures dwindling into objects of perception, which implies that they are images of the fall of man" (FS 42).

All the above discussion may lead us to some vertical spiritual reality besides the horizontal reality of time as eternal and space as infinite and all as indefinite, which is a physical reality. This vertical reality is the reality of the Spirit. As we can see above, the unfallen Adam and Eve and all others are different from the fallen beings in fact and enjoy different spiritual exuberance, but according to the horizontal perception, there is no difference at all. When we are conscious of the fact that the different cultures, societies, ideologies, psychological states and other realities are within the range of human creativity and are all manifestations of the Spirit and that it is the Spirit that matters, we are at the top of this vertical dimension, enjoying most spiritual freedom and exuberance, like wind, substantial but unpredictable, as Jesus tells Nicodemus. We will also be able to cherish the life in others better than they can appreciate it themselves, which is the basis for love as a primary principle of Christianity. As consciousness of life decreases, we descend on the vertical line, until we reach the bottom where we hold that our hope and faith are illusions and the only reality is the mechanical world, which means the vertical dimension is simply neglected. This vertical fact is what Jacob's ladder is, the bottom of which is the stone, a symbol of the mechanical world, while the top is his highest intensity of life in the dream, as is expressed in Frye's words:

It is the illusions of literature that begin to seem real, and ordinary life, pervaded as it is with all phony and lying myths that surround us, begins to look like the real hallucination, a parody of the genuine imaginative world. (MM 77-8)

So, the same creature, if we perceive it with different imaginative perceptions, will be able to take on different spiritual forms, which is why a creature can be sanctified with prayer and thanksgiving after which our intensity of life increases and we can enjoy it more, for both the enjoyer and the enjoyed have taken on a spiritual, or metaphorical significance.

The lack of consciousness of this dimension makes philosophy handicapped, like what happened in Nietzsche--though having tried to become a superman, he remained still in this world and got no upward resurrection, for he projected his spiritual fact, his mythopoeic creation, in the world of physical reality. This rationalization of the Word of Spirit and projection of imaginative creativity into a superficial reality, which is an oblivion of the spiritual dimension, a real dimension of humanity, can account for Frye and his guru and other prophets' cold reception.

\section{Recognition}

\subsection{Spirit as the Dianoia of Literary Mythos}

In the Anatomy of Criticism Frye based his purpose on what he thought of as the ambition of Aristotle's Poetics--to 
develop an "intelligible structure of knowledge attainable about poetry which is not poetry itself, or the experience of it, but poetics" (AC 14), and in the whole work we find a consciousness of keeping Aristotle in sight, an evidence of which is that in the beginning of all the four essays there is Aristotle mentioned. Here we find a similarity between Heidegger and Frye--redefining already existent definitions in a new and expanded sense. Recognition, the turning point in Aristotle's mythos, "a change from ignorance to knowledge" which may be a revelation of a certain person's identity, which "leads either to love or to hatred between persons destined for good or ill fortune" (Aristotle 46), is a term frequently employed in many of Frye's major works with an almost infinitely expanded implication. In Faulkner's A Rose for Emily, the last part is a recognition scene first in Aristotle's sense, i.e. we have a mystery discovered. From the beginning to the end we grow more and more concerned to know the mystery clustered around the main character--Emily. Her house becomes a focus of our curiosity, so when the townspeople broke into "the region which no one had seen in forty years", they were doing what we wish to do. The mystery is revealed and our curiosity met, and we come out of ignorance into knowledge. But if recognition stops on this level, there would be no difference between this short story and a commonplace mystery story or detective story. The next question we should ask is: as in Aristotle's definition, the change from ignorance to knowledge will lead to something, what will this change lead to? When we read it for another time, we see there is another sense of recognition on a higher level. Emily's identity as a representative figure of the upper class of the old South (Li 115) and thus a focus of two ideologies competing to get the upper hand makes us no less curious about her choice of life than the townspeople. The house becomes a symbol of social competition, a focus of the society and history. The recognition scene signifies an end of a historical era (Li 117). But we find still that something is missing, for what Emily did not only subverted the expectation of the Old South upper class, but also that of the new industrial materialist class, and there seems in her something beyond all ideologies; and what's more, we are still not fully conscious what this recognition would lead to. With this insight, when we read it again we find that representatives of the Old South as well as the common people all try to pin Emily down to some predictability despite the difference of their directions, which means that though from the surface the two classes' treatments of Emily are different, they are the same in their wish to control, which are all because of Emily's peculiar identity. But in the recognition scene, when we see the "room decked and furnished as for a bridal", the "faded rose color", the crystal, man's toilet things and others, we find that her identity as a representative of the Old South is only an illusion of the townspeople, and that her real identity as an individual trying to create her own universe, to enjoy her real life, remains neglected and, more disappointingly, severely repressed. Only when we grow conscious of this do we have really an identity of a person revealed (Aristotle 46) and are ready to discover what kind of reversal does this recognition scene brings. After the failure of all people's effort to reduce Emily to their control under predictability, there is a transformation of atmosphere. The bickering about ideologies, conventions and all fade away into meaninglessness, and the people are shocked into another world totally different from the past one; and it seems there is a recognition scene in everyone in that they suddenly become conscious how far away they have left their genuine life. The atmosphere also tries to incorporate the reader. During the whole reading process, he is as curious about Emily as the townspeople, and in him also there is no genuine care for Emily herself. As we have analyzed above, the reader's effort in mystery discovery and the reduction of someone to a social and historical position is as great. Up to now, the shocked group also includes him, i.e. more than being a spectator, he becomes a partaker of this atmosphere, which is why Frye insisted many times that the recognition of identity does not only belong to characters but belongs more to readers as well. With this consciousness, when we read the story again, we will find that every word now takes on a new meaning and significance and there is a sympathy with the restricted life as intense from the beginning to the end. Those unintelligible or seemingly negligible details all are included in the same spiritual unity, i.e. we can see now the whole spirit even in a single word, which is the way the concept dianoia of Aristotle is expanded and redefined by Frye (FI 24).

This analysis, when going over it again, can serve as another illustration of Frye's "standing back" principle (AC 140), with the first sense of recognition corresponding to the textual or rhetorical analysis which is the first step, the second sense corresponding to the realistic analysis while the third sense corresponding to the archetypal one and the last reading being informed by literature as a self-contained universe (AC 118) with its basis on "a central life" which "is the life of humanity" with "the verbal imagination of man" as the "inspired teacher" (CP 128). We see how the mythos gives narrative to the dianoia, which is the same as saying that the body gives narrative to the spirit, and how the dianoia gives significance to the mythos, which is to say that the spirit bequeaths life to the body; which is one aspect of what the important concept of "interpenetration" signifies for Frye. When informed by this "central life", we may push this spiritual dimension beyond the bondage of one literary work and see a certain literary work, say, Romeo and Juliet, which we may have never associated with A Rose For Emily as the same story with it. Here we also have two sides fighting against each other whose life is a life of position and contention, each wishing to restrict the scope of another, which is the same as what we have found in A Rose for Emily. The genuine life, the 
imaginative and spirited innocent love, is both neglected and restricted, as what happened to the Emily as a real individual. Finally, it is by the sacrifice of the life that the two sides--Capulet and Montague--realize how much genuine life they have restricted with their meaningless and fruitless hatred (Act 5, Scene 3, lines 291-5), which is the same as what happened in Emily's case-the revelation of how life had been throttled by meaningless position and contention shocked the townspeople and the reader to the same peace in the Spirit, which is the same "glooming peace" (Act 5, Scene 3, line 305). Thus we have here the same recognition scene, the same returning to the real identity. Our sympathy is the same sympathy and it is always latent in our mind what things should be like. The happiness of Emily and Romeo and Juliet, the fulfillment of their genuine wish is always there and it is the absence of it that fills us with pathos. So, informed by this insight, we see that in Romeo and Juliet too, every detail takes on the significance of the whole unity and the spirit is everywhere the same giving significance to the narrative. What we have discovered here, i.e. identity of spirit concealed under a seemingly large gap between surfaces is the same as what Frye discovered and stated again and again about Blake and Milton to the effect that they are the same and that sameness (identity) leads to individual variety while similarity leads to lifeless monotony.

This informing spirit exists not only in these two works which have a clear recognition scene but also in those which have not. When Adam thrusts the blame of his sin to Eve and Eve to the snake in a desperate struggle to get back their paradise and when Macbeth tries to fight against a world of alienation and potential danger to avoid the inevitable doom, there is the same thing in us that wishes that they should be restored to their Holy state. This is why Frye said: "This world is frequently called (in Buddhism, for example) an unborn world. Its presence, however, or, more accurately, the lively feeling of its absence, is what accounts for the quality of pleasure in the arts" (CP 168) (The emphasis is mine.). Later in the text (169) Frye called it joy rather than pleasure, for it is a better word to describe what we get from pure spiritual creation which belongs to free life. Since Anatomy of Criticism is the most widely read work of Northrop Frye, it should be familiar to most of us that in this work, where he provided the archetypal structure for the grammar of literature, his cosmic design for narratives is a combination of the cyclical movement and the dialectical movement, the latter a movement along the vertical line from apocalyptic imagery to demonic imagery or vice versa while the former a circle; which results in four mythoi. And the four may be seen as one whole marching from the romantic adventures to the death and absence of the heroism and effective action and finally to the newborn society around a mysterious hero and his bride (AC 192). But the whole cycle, as we see, according to the arrangement by Frye, ends with comedy. In the end of his essay on the theory of myths, we see that he does not stop with pure irony but perseveres, passes "a dead center", and finally sees "the gentlemanly Prince of Darkness bottom side up" (AC 239). And this Prince is gentlemanly because Frye now is above him, free of his bondage, and can sense the joy of life in the creation even of absolute ironies. So, even in the highly structural analysis of the whole context of literature, we can detect Frye's effort to liberate the pure life in literature out of the bondage of its variety of archetypal narratives, which corresponds to his effort to reach from the archetypal phase to the anagogic phase of meaning and which is why he pays so much attention to comedies.

Sometimes the spirit will not be so patient to hide itself behind but will have its own voice clearly emerge, which we may see in the last scene of The Winter's Tale, a scene Frye frequently returned to. What is peculiar about this scene is that in it we see not rebirth, signified by the flourishing youth and spring, but resurrection, the all-life-and-no-death, for the final prosperity does not only include Perdita and Florizel, the prince and princess, but also Hermione and Leontes, the old and past. With Music and sculpture, which are forms of art, there is the revival of the dead past, as with the help of the Spirit Ezekiel prophesied and made alive dry bones (Ezekiel 37) (GC 72). That's also what Frye said historians should be doing--giving form to chaos (FS 29), discovering our buried lives and thus making us conscious of our own spirit to enable us to be more alive, which is another illustration of how social sciences are informed by literature and mythology.

Thus what we find in literature is a narrative permeated everywhere by the Spirit which strives sometimes to come out of the--though revealing, but concealing as well--narrative and become bold proclamation, which can account for Frye's taking spirit as the human initiative excluded from literature. Readers informed by this spiritual vision would be able to read life into literary works and detect the Spirit as the designer everywhere, which means that it is the Alpha and Omega, the first and the last in the literary universe. He would be able to pass over the mythos in literature and see a new order of heaven and earth in which the old order of things is folded up (Revelation 21) and the restriction of life, which is death and hell, is once and for all cast into the eternal lake of consuming fire which is the abovementioned discipline of the free man (Revelation 20: 14). At this point he would be able to see the Dianoia of the whole literary Mythos-the Spirit in the Word and the Word in the Spirit, which is what a recognition scene in one's verbal experience signifies for Frye (WTC 108).

\subsection{Spirit as an Omnipresent Designer}

As a work belongs both to literature and to proclamation, naturally, The Bible has made it most clear that the Spirit 
is the underlying unity which is in all, above all and through all (Ephesians 4: 4-6) and whoever speaks against the Spirit will not be forgiven though words against the Word can be (Matthew 12:31-2; Luke 12: 10). We have already mentioned above that it is the Spirit of God who is in a poetic creation of the universe, the first effort of the spiritual transformation of the body. In the whole Bible, what we see is one recreation after another the story of raising life from death. In Exodus, when plague after plague falls upon the spiritual (metaphorical) Egypt, the Lord, the Spirited Creator, says boldly that it is He who has hardened the heart of Pharaoh and his servants, the prince of this world, so that he can show his signs before them and by showing favor to the spiritual (metaphorical) Israelites, tell all that he is the Lord; which means that Pharaoh and the Egyptians and the Israelites should act in such a way as to make the Spirit glorified. In the above analyses of secular literature, we have seen that life should go through the most severe restriction, i.e. the darkest hell, in order to call all into the unity of the spirit. The Bible here tells us with the direct voice from the Spirit himself that these are not from outward objective history or description of the social realities but are from his own creative design. The suffering of Emily's individuality and the townspeople's neglect of real life are the same as the suffering of the Israelites and the hardening of the Egyptians' heart and all of these are not from the subjective human will or objective facts but the Holy Spirit in the creative prophetic artist; thus we see that in the abovementioned miracle of bequeathing life to dry bones it is the Spirit that carried Ezekiel out (Ezekiel 37: 1) and accomplished it while the prophet is a medium for the full function of the Spirit.

So, as a work surpassing literature in the intensity of spirit, the human initiative excluded in literature in the Bible enjoys a more conscious domination. Since the Bible elevates what is implicit in literature into the explicit, the conscious level, the study of it would surely be proved enlightening for a coherent knowledge of literature; thus, it's not strange that the conclusions drawn from the inductive study can match so well with words in the Bible. As the conclusions drawn are based on Frye's literary insight, we see very well how his insight corresponds to the Bible, which is another clear evidence that he and the prophetic writers are inspired by the same thing--the Holy Spirit.

Up to now, we have gone through the whole process from the lowest level of recognition as the discovery of a mystery to the recognition of genuine identity of the main character, all characters and finally the reader as well. Then we moved beyond one work to a comparative study of two works and recognized the common spirit inside them despite the gap between the centrifugal meanings, which led us further into the recognition scene of our verbal experience and gave us the consciousness that the Spirit, the creative life, the "central life" of humanity, is the informing power of all literary works and all genuine literary experiences. But still, we need to push the horizon further back beyond the bondage of literature and see how to have this recognition scene in actual life, which is to some extent resisting our spiritual transformation, to make our life as spirited.

\section{Conclusion}

Looking back at the course I have followed, I find to my surprise how it is like the structure of one of Frye works. Not only the fall-and-rise design, but also the way from the logical argument to concrete books and finally to the end in which the Spirit, the free flow of a common energy reigns, are all prominent features of Frye's works and articles. As Frye has pointed out, that he unconsciously imitated his guru Blake, I find myself unconsciously following Frye's argument. When Frye tried to base criticism on literature, we see his theory is less like a theory than a consciously kerygmatic literary work, making him, as we have said above, a theorist with a poetic temperament. When I try to trace Frye's thought as he himself has thought it, I find that my argument also is less an argument than another effort to release the essence of humanity. The struggle from logic to something beyond logic but enclosing it is the same. Thus the argument is not a cause-and-effect demonstration, which is, to Frye, based on reason, sticking to the memory of the past and taking it as the basis of the future, a Lockian perspective; instead, the argument follows the course which Frye holds that the Bible does--typology, which is based on faith, love and hope, on the belief that the Spirit is the only Truth. Thus, it is not the logical power that pushes the argument, as well as Frye's theory, on, but the call of life from the deepest part of the Eternal Heart. The consciousness of this Spiritual power and the spiritual life style of love, faith and hope are what made Frye devote so much effort to comedy. Thus, the attempt of Frye's quest, and the genuinely prophetic writers' whose fruits are the starting point for Frye, as well as this study on Frye, are in essence the same attempt to make us more conscious of life and thus raise up the intensity of the joy of its creative power by casting away the restriction of life: the sense of otherness, the fear of death, the submission of life to physical rules, making them a philosophy of life, and the sacrifice of our genuine personality to continuity, foolish consistency and conformity, etc. Which is why the thesis is entitled "The fable of recognition", for prophetic literature, kerygmatic works, Frye's quest and my study are of no difference as far as the centripetal meaning is concerned. It is a fable; not a persuasive argument, but an effort to wake the reader up to his own spiritual identity, because it can only provide the story, and the reader, as Frye said, is to choose whether to enter the spirit or not; not a doctrine, for without spiritual awareness, doctrines remain in the phase of laws, as illustrated above, and are more of a bondage than a way to freedom. 
So we can now be sure that Frye is neither a myth-archetypal critic, nor a structuralist, nor a psychologist, not even a figure of culture studies if this field is seen in the present perspective, for we have seen how he has shown his dissatisfaction with contemporary critics' studying men as products of cultural mutations without acknowledging the Essence of Man. These attempts to classify Frye can provide no insight helpful in our understanding of him, and what they can provide, as Frye said (FS 15) most studies of Blake had provided, is information about the social anxiety and taste of a certain time. As far as centripetal meaning or spirit is concerned, Frye is closer to pre-Romantic and Romantic poets like Blake and Wordsworth, transcendentalists like Emerson and Thoreau, Taoist philosophers like Zhuang $\mathrm{Zi}$ and Lao $\mathrm{Zi}$ and Buddhists who hold that awareness of the light of our genuine nature is the core, than he is to any archetypal critic, structuralist or scholar in the field of culture studies. With this enlightenment, Frye's thought will not remain handicapped by this foolish classification of little minds, neither will its application scope be limited to the margin of humanity. Utopian dream and aesthetic humanism will finally be replaced by a central place in the course of the race destined for human beings. The spirit informing Frye, all prophetic writers, all poetically dwelling lives and all fruits of positive human activities will become an informing power opening our eyes to all Truth, making us more consciously creative, shedding our genuine personality and thus giving life to all around. This is where thought ends and life begins; where criticism ends and the possession of literature begins.

\section{References}

Abrams, M. H. (2004). A Glossory of Literary Terms: Seventh Edition. Foreign Language Teaching and Research Press \& Thomson Learning.

Aristotle. (1999). On the Art of Poetry. Trans. T. S. Dorsch. Beijing: Social Science Press of China.

The Bible. King James Version.

Denham, Robert. (1978) . "Introduction." Northrop Frye on Culture and Literature: A Collection of Review Essays. Comp. R Denham. Chicago and London: The University of Chicago Press.

Denham, Robert. (2004). Northrop Frye: Religious Visionary and Architect of the Spiritual World. Charlottesville and London: University of Virginia Press.

Eagleton, Terry. (1983).Literary Theory: An Introduction. Oxford: Blackwell.

Faulkner, William. (2000). “A Rose for Emily.” Selected Readings in British and American Literature. Ed. Kong Ying et. al. Beijing: Higher Education Press.

Frye, Northrop. (1957). Anatomy of Criticism-Four Essays. Princeton: Princeton University Press,

---. (1980). Creation \& Recreation. Toronto: University of Toronto Press.

---. (1971).The Critical Path: An Essay on the Social Context of Literary Criticism. Bloomington and London: Indiana University Press.

---. (1963). Fables of Identity: Studies in Poetic Mythology. N.Y.: Harcourt, Brace and World.

---. (1947). Fearful Symmetry: A Study of William Blake. Princeton: Princeton University Press,

---. (1982). The Great Code: The Bible and Literature. N.Y.: Harcourt Brace Jovanovich.

---. (1978). Northrop Frye on Culture and Literature: A Collection of Review Essays. Comp. Robert D. Denham. Chicago and London: The University of Chicago Press.

---. (1976). Spiritus Mundi: Essays on Literature, Myth and Society. Bloomington: Indiana University Press.

---. (1963).The Well-Tempered Critic. Bloomington: Indiana University Press.

---. (1990). Words with Power: Being a Second Study of "The Bible and Literature." New York: Harcourt Brace Jovanovich.

Higdon, David Leon. (1989). "The Relevance of Northrop Frye's 'Specific Continuous Forms”. Rocky Mountain Review of Language and Literature, vol. 43, No. 4, p.223-234. doi:10.2307/1347010, http://dx.doi.org/10.2307/1347010

Li, Yang. (2006). The Change of American Literature in the Post-Modern Age. Jinan: Shandong University Press.

Liu, Kang. (2002). "Universalism, Easthetics and Utopia”. Frye Study: East and West. Ed. Wangning \& Xu Yanhong. Beijing: China Social Science Press, 1996. Shakespeare, William. The Completed Works. Ed. Stephen Orgel and A.

R. Braunmuller. Penguin Books. 
Xie, Shaobo. (1996). "History and Utopian Desire: Frederic Jameson's Dialectic Tribute to Northrop Frye." Culture Critic. No. 34. (Autumn, 1996), 115-142. doi:10.2307/1354614, http://dx.doi.org/10.2307/1354614

Xiao, Jinlong. (2004).The Nature of Derrida's Deconstruction. Beijing: China Social Science Press.

\section{Abbreviations (In Alphabetical Order)}

AC: Anatomy of Criticism

CP: Critical Path

CR: Creation and Recreation

EI: Educated Imagination

FI: Fables of Identity

FS: Fearful Symmetry

GC: Great Code

LN: Northrop Frye's Late Notebooks

MM: Myth and Metaphor

NFCL: Northrop Frye on Culture and Literature

SeS: Secular Scripture

SM: Spiritus Mundi

StS: Stubborn Structure

WP: Words with Power

WTC: Well-Tempered Critic 